\title{
VARIABILIDADE GENÉTICA DO RENDIMENTO INTRÍNSECO DE GRÃOS EM GERMOPLASMA DE COFFEA ${ }^{(1)}$
}

\author{
CRISTIANA DE GASPARI-PEZZOPANE ${ }^{(2,3)}$; HERCULANO PENNA MEDINA FILHO ${ }^{(2,4)}$; \\ RITA BORDIGNON ${ }^{(2)}$
}

\begin{abstract}
RESUMO
O rendimento intrínseco do café, relação percentual entre a massa de dois grãos normais tipo chato e do respectivo fruto que os contém, foi estudado em seis grupos de germoplasma de Coffea, com o objetivo de se conhecer a variabilidade genética para essa característica. Investigou-se o rendimento intrínseco de Coffea arabica em um grupo de cinco cultivares de porte baixo, em outro contendo 22 cultivares e seleções e, ainda, em outro grupo com 79 cultivares, variedades e formas botânicas, mutantes e acessos da Etiópia. Em C. canephora, foram analisados três acessos da variedade kouilou e 10 acessos da variedade robusta. Investigaram-se ainda, outras oito espécies do gênero Coffea. Observou-se considerável variabilidade genética tanto entre representantes de C. arabica quanto de C. canephora, assim como entre as diferentes espécies do gênero Coffea. A amplitude de variação nos valores de rendimento intrínseco referente ao último grupo foi bem maior que a de qualquer outro grupo estudado. A magnitude das variações observadas e as implicações econômicas do rendimento intrínseco indicam que essa característica pode ser utilizada como um critério adicional de seleção no melhoramento de C. arabica e C. canephora.
\end{abstract}

Palavras-chave: café, grãos tipo chato, melhoramento, cultivares, polpa.

\section{ABSTRACT \\ GENETIC VARIABILITY FOR BEAN INTRINSIC OUTTURN IN Coffea GERMPLASM}

The intrinsic coffee bean outturn, percent weight ratio of two normal flat beans and the respective whole fruit, was studied in six Coffea germplasm groups in order to investigate the genetic variability for this characteristic. It was evaluated in C. arabica a group of five short stature cultivars, another group composed of 22 cultivars and selections yet a third group of 79 items comprising cultivars, botanical varieties and types, mutations and accessions from Ethiopia. In C. canephora it were studied three acessions of var. kouilou and ten of var. robusta. It were investigated also eight other species of the genus Coffea. Considerable genetic variability was detected within C. arabica and C. canephora and among the other species of the genus Coffea. The range of values among the last group was much larger than in any other group investigated. The magnitude of variations and the economic implication of bean intrinsic outturn indicate that this characteristic could be used as an additional selection criterion in improvement programs aiming at the development of high yielding cultivars of $C$. arabica and C. canephora.

Key words: coffee, flat beans, breeding, cultivars, pulp.

$\left({ }^{1}\right)$ Parte da dissertação de mestrado da primeira autora em Agricultura Tropical e Subtropical, apresentada ao Instituto Agronômico (IAC), em Campinas. Recebido para publicação em 14 de maio de 2003 e aceito em 4 de fevereiro de 2004.

$\left({ }^{2}\right)$ Centro de Análise e Pesquisa do Agronegócio do Café 'Alcides Carvalho', Instituto Agronômico (IAC), Caixa Postal 28, 13001-970, Campinas (SP). E-mail: medina@iac.sp.gov.br; rita@iac.sp.gov.br

$\left({ }^{3}\right)$ Com bolsa de Pós-Graduação da CAPES.

$\left({ }^{4}\right)$ Com bolsa de Produtividade em Pesquisa do CNPq. 


\section{INTRODUÇÃO}

Uma importante característica econômica no melhoramento do cafeeiro é o rendimento, ou seja, a relação entre a massa de café maduro ou seco e o de café beneficiado. Na prática, os produtores se referem ao rendimento ou renda do café como a proporção entre a "palha" que sobra do beneficiamento do fruto inteiro e o resultante "café limpo". Em C. arabica essa proporção em massa varia normalmente entre $45 \%$ e $55 \%$ (KRUG et al., 1965). O rendimento, assim estimado, sofre considerável influência da quantidade de frutos-bóia, os quais são desprovidos de grãos ou que contém apenas um grão tipo chato e também da quantidade de frutos que contém um grão moca (VACCARELli et al., 2003).

Entretanto, o rendimento aqui estudado e denominado rendimento intrínseco ${ }^{(5)}$ refere-se somente à relação percentual entre a massa seca de dois grãos normais tipo chato e a massa seca do respectivo fruto contendo esses dois grãos. Livre das grandes variações devido aos frutos-bóia e às sementes do tipo moca, exprime uma relação mais acurada entre a massa de grãos e as demais estruturas do fruto que os contém. Presumivelmente, esse parâmetro seria de maior valia para indicar as diferenças existentes entre materiais genéticos distintos.

As principais espécies de Coffea no mercado mundial são $C$. arabica, originária da Etiópia, Sudão e Quênia e C. canephora, oriunda de regiões tropicais e subtropicais do continente africano (LEBRUN, 1941; Chevalier, 1947; Charrier, 1978). C. arabica, conhecida genericamente como café arábica, é responsável por $75 \%$ da produção comercializada e preferida devido à melhor qualidade de sua bebida. C. canephora, conhecida como café robusta, contribui com $25 \%$ desse mercado, tendo ampla utilização na indústria de café solúvel e em blends com café arábica, visando à redução no preço do produto final.

No gênero Coffea existem outras 80 ou mais espécies, sendo 25 provenientes do continente africano e 55 de Madagascar e Ilhas Mascarenhas (BRIDSON, 1982; 1987; 1994; BridSON e VerdCOURT, 1988). Tais espécies, embora não apresentem expressão comercial, são importantes para o melhoramento genético, pois se constituem em reservas gênicas de resistência às pragas, doenças e condições adversas de ambiente (Medina Filho et al., 1984; Carvalho e Fazuoli, 1993).

$\left({ }^{5}\right)$ H.P. Medina Filho; R. Bordignon. (dados não publicados)
C. arabica, com $2 n=4 x=44$ cromossomos é a única espécie poliplóide do gênero, sendo as demais, diplóides com 22 cromossomos. C. canephora é alógama e apresenta auto-incompatibilidade gametofítica (CONAGIN e Mendes, 1961; Berthaud, 1980), enquanto C. arabica multiplica-se predominantemente por autofecundação, com taxa de fecundação cruzada ao redor de $10 \%$ (CARVALHO e MÔNACO, 1962).

As outras espécies são alógamas e, em grande maioria, auto-incompatíveis. Sendo C. arabica autógama, a variabilidade genética entre as plantas não é alta devido ao fato de as cultivares terem sido desenvolvidas, na maioria dos casos, pelo método genealógico. Como C. canephora é auto-incompatível apresenta, em geral, maior variabilidade genética, sendo as cultivares constituídas de mistura de progênies de meios-irmãos. Cultivadas em larga escala no Estado do Espírito Santo, as recentes cultivares selecionadas pela INCAPER são, entretanto, constituídas por cerca de dez clones propagados vegetativamente. Nas outras espécies de Coffea, a variabilidade genética é mais elevada, por serem alógamas e não terem passado pelo processo de melhoramento e seleção.

O objetivo deste trabalho foi investigar a característica rendimento intrínseco em diferentes germoplasmas de C. arabica, C. canephora e de espécies silvestres do gênero Coffea do Banco de Germoplasma do Instituto Agronômico (IAC).

\section{MATERIAL E MÉTODOS}

\subsection{Germoplasmas analisados}

O rendimento intrínseco (RI) foi estudado em seis grupos independentes de materiais genéticos, em 2001, descritos a seguir:

Grupo 1: Cultivares de C. arabica de porte baixo - Centro Experimental Central (CEC), Campinas

Nesse primeiro grupo, foram estudadas as cultivares de porte baixo Catuaí IAC 81, Catuaí IAC 144, Obatã IAC 1669-20, Tupi IAC 1669-33 e Ouro Verde IAC H5010-5, mantidas em um lote no Centro Experimental Central (CEC) do Instituto Agronômico (IAC), em Campinas. Em cada cultivar, coletaram-se 100 frutos de quatro plantas na posição mediana, face Norte, sendo os valores de RI analisados no delineamento inteiramente casualizado.

Grupo 2: Cultivares e seleções de C. arabicaFazenda Monte D'Este 
Na Fazenda Monte D'Este, localizada em Campinas, seleções de diversas cultivares de porte alto e de porte baixo são mantidas em um campo experimental homogêneo e com produções controladas, visando a observações comparativas. Em cada uma das 22 cultivares e seleções relacionadas na Tabela 1 foram colhidos um total de 100 frutos, amostrando-se quatro plantas inteiras. Os resultados de RI foram analisados segundo o delineamento inteiramente casualizado.

Tabela 1. Relação de cultivares e seleções de C. arabica da Fazenda Monte D'Este, Campinas (SP), avaliadas no Grupo 2

\begin{tabular}{|c|c|}
\hline Identificação & Cultivar/Seleção \\
\hline 1 & Bourbon Amarelo IAC LCJ-18 \\
\hline 2 & Mundo Novo Vermelho IAC 388-17-1 \\
\hline 3 & Acaiá IAC 474-10 \\
\hline 4 & Ouro Verde IAC 4395 \\
\hline 5 & Catuaí Vermelho IAC 46 \\
\hline 6 & Catuaí Vermelho IAC 81 \\
\hline 7 & Catuaí Vermelho IAC 99 \\
\hline 8 & Catuaí Amarelo IAC 47 \\
\hline 9 & Catuaí Amarelo IAC 62 \\
\hline 10 & Catuaí Amarelo IAC100 \\
\hline 11 & Obatã IAC 4092 \\
\hline 12 & Tupi IAC 4096 \\
\hline 13 & Catucaí Vermelho MAPA \\
\hline 14 & Catucaí Amarelo MAPA \\
\hline 15 & Icatu Vermelho IAC 4041 \\
\hline 16 & Icatu Vermelho IAC 4043 \\
\hline 17 & Icatu Vermelho IAC 4045 \\
\hline 18 & Icatu Vermelho IAC 4046 \\
\hline 19 & Icatu Amarelo IAC 2944 Broto Bronze \\
\hline 20 & Icatu Amarelo IAC 2944 Broto Verde \\
\hline 21 & Icatu Amarelo IAC 2944-6 \\
\hline 22 & Icatu Amarelo IAC 2944-7A \\
\hline
\end{tabular}

Grupo 3: Variedades e formas botânicas, híbridos, acessos e mutantes de C. arabica - coleção no CEC

Variedades e formas botânicas, mutantes e acessos de C. arabica da Etiópia, representando grande diversidade genética da espécie, são mantidos em uma coleção viva no CEC. Nesse lote, 100 frutos da planta toda foram coletados em uma planta de cada um dos 79 acessos estudados (Tabela 2). Os resultados do RI foram analisados de acordo com o delineamento inteiramente casualizado.

Grupo 4: Seleções de C. canephora var. kouilou - Banco Ativo de Germoplasma (BAG) no CEC

Foram coletados 100 frutos em uma planta inteira das coleções IAC 66, IAC 67 e IAC 68 da variedade kouilou de C. canephora, oriundas do Estado do Espírito Santo, mantidas no BAG do CEC em Campinas. Na análise dos dados, considerou-se o delineamento inteiramente casualizado.

\section{Grupo 5: Acessos de C. canephora - Ensaio no CEC}

Foram investigados dez acessos de $C$. canephora oriundos do Ceilão, mantidos em condições de experimentação no CEC, em Campinas, relacionados na Tabela 12. Coletaram-se 100 frutos em cada uma das duas plantas de cada acesso sendo as amostras constituídas da mistura de frutos da planta toda. Considerou-se para análise dos dados o delineamento hierárquico totalmente aninhado, e os frutos em cada planta, o fator de aninhamento.

\section{Grupo 6: Espécies de Coffea - BAG no CEC}

As seguintes espécies presentes no BAG do Instituto Agronômico de Campinas e depositadas em Herbário foram avaliadas: C. liberica var. liberica 38414; C. liberica var. dewevrei 29; C. klainii 42265; C. dybowiskii 38413; C. eugenioides 42276; C. stenophylla 42277; C. salvatrix 42278; C. racemosa 42279; C. congensis 42280; C. kapakata 42282; C. canephora cv. Guarini 38462. Reflexo da diversidade genética desses materiais, a época de maturação é bastante variável. Por essa razão, frutos cereja foram coletados à medida que amadureciam, nas várias partes e faces das plantas, até completarem um total de 100 frutos. Os dados foram analisados pelo delineamento inteiramente casualizado.

\subsection{Preparo dos frutos para obtenção do rendimento intrínseco}

Foram coletados frutos em lotes experimentais e coleções adultas, com idades, espaçamentos e tratos culturais diversos, porém uniformes em cada grupo analisado.

Frutos no estádio de maturação cereja foram colhidos na safra de 2001, secos em terreiro pavimentado e padronizados a $12 \%$ de umidade após ficarem aproximadamente 30 dias em sala com ar condicionado. O monitoramento da padronização da umidade foi obtida por pesagens sucessivas de amostras extras de frutos, secas em estufa a $105^{\circ} \mathrm{C}$ durante 24 horas. 
Tabela 2. Relação de variedades e formas botânicas, híbridos, acessos e mutantes de C. arabica, provenientes do Banco Ativo de Germoplasma (BAG) do Centro Experimental de Campinas (CEC), analisados no Grupo 3

\begin{tabular}{|c|c|c|}
\hline Identificação no Experimento & Identificação no BAG & Descrição \\
\hline 1 & IAC Catuaí Amarelo (mistura) & Variedade \\
\hline 2 & IAC Catuaí Vermelho (mistura) & Variedade \\
\hline 3 & IAC Mundo Novo (mistura) & Variedade \\
\hline 4 & IAC $1133-2$ & Acesso \\
\hline 5 & IAC Bourbon Amarelo (mistura) & Variedade \\
\hline 6 & IAC Nacional & Variedade \\
\hline 7 & IAC 1130-23 & Acesso \\
\hline 8 & IAC 1105-1 & Acesso \\
\hline 9 & IAC 1109-3 & Acesso \\
\hline 10 & IAC Sumatra & Forma \\
\hline 11 & IAC Bourbon Puro & Forma \\
\hline 12 & IAC Mucronata & Mutante \\
\hline 13 & IAC 1106-6 & Acesso \\
\hline 14 & IAC Laurina & Mutante \\
\hline 15 & IAC Erecta & Variedade \\
\hline 16 & IAC Cioicie & Variedade \\
\hline 17 & IAC 1142-1 & Acesso \\
\hline 18 & IAC 2119-2 & Acesso \\
\hline 19 & IAC Variegata & Mutante \\
\hline 20 & IAC Glaucia & Forma \\
\hline 21 & IAC 1134-1 & Acesso \\
\hline 22 & IAC H 7312 & Híbrido (Catuaí IAC 81 X São Bernardo) \\
\hline 23 & IAC 1151-4 & Acesso \\
\hline 24 & IAC 3376 & Acesso \\
\hline 25 & IAC 1166-29 & Acesso \\
\hline 26 & IAC 2186-3 & Acesso \\
\hline 27 & IAC 1153-1 & Acesso \\
\hline 28 & IAC Volutifolia & Mutante \\
\hline 29 & IAC 1162-3 & Acesso \\
\hline 30 & IAC 1132-18-2 & Acesso \\
\hline 31 & IAC Híbrido de Timor & Acesso \\
\hline 32 & IAC Caripe & Variedade \\
\hline 33 & IAC Anômala & Variedade \\
\hline 34 & IAC $1129-8$ & Acesso \\
\hline 35 & IAC 1171-13 & Acesso \\
\hline 36 & IAC Amarelo de Botucatu & Variedade \\
\hline 37 & IAC Abramulosa & Mutante \\
\hline 38 & IAC 1110-4 & Acesso \\
\hline 39 & IAC Bourbon Vermelho (mistura) & Variedade \\
\hline 40 & IAC 1170-1 & Acesso \\
\hline 41 & IAC 1137-5-6 & Acesso \\
\hline 42 & IAC H 7681 & Híbrido (Mundo Novo X Villa Lobos) \\
\hline 43 & IAC Goiaba & Mutante \\
\hline
\end{tabular}


Quadro 2. Conclusão

\begin{tabular}{|c|c|c|}
\hline Identificação no Experimento & Identificação no BAG & Descrição \\
\hline 44 & IAC 1131-9 & Acesso \\
\hline 45 & IAC Cera & Mutante \\
\hline 46 & IAC BA 27 & Acesso \\
\hline 47 & IAC Icatu Vermelho (mistura) & Forma \\
\hline 48 & IAC Polisperma & Mutante \\
\hline 49 & IAC Pálido Virides & Mutante \\
\hline 50 & IAC $1147-3$ & Acesso \\
\hline 51 & IAC São Bernardo & Variedade \\
\hline 52 & IAC Abssínica & Variedade \\
\hline 53 & IAC Caturra Vermelho & Variedade \\
\hline 54 & IAC $1123-17$ & Acesso \\
\hline 55 & IAC $1155-2$ & Acesso \\
\hline 56 & IAC Semierecta & Mutante \\
\hline 57 & IAC $1135-13$ & Acesso \\
\hline 58 & IAC $1136-5$ & Acesso \\
\hline 59 & IAC $1116-4$ & Acesso \\
\hline 60 & IAC 3377 & Acesso \\
\hline 61 & IAC 1141 Amphyllo & Variedade \\
\hline 62 & IAC 1139-7 Sudan Rume & Variedade \\
\hline 63 & IAC H 7337 & Híbrido (Erecta x Catuaí) \\
\hline 64 & IAC 1107-5 & Acesso \\
\hline 65 & IAC H 7702 & Híbrido (Bourbon X Pacas) \\
\hline 66 & IAC Vila Sarchi & Variedade \\
\hline 67 & IAC $1138-18$ & Acesso \\
\hline 68 & IAC Purpurascens & Mutante \\
\hline 69 & IAC 1128-1 & Acesso \\
\hline 70 & IAC Angustifolia & Mutante \\
\hline 71 & IAC Icatu Caturra & Forma \\
\hline 72 & IAC Caturra Amarelo & Variedade \\
\hline 73 & IAC Iarana & Forma \\
\hline 74 & IAC Catimor & Acesso \\
\hline 75 & IAC $1127-7$ & Acesso \\
\hline 76 & IAC Murta & Variedade \\
\hline 77 & IAC Macrodiscus & Mutante \\
\hline 78 & IAC Enarea & Variedade \\
\hline 79 & IAC $1103-3$ & Acesso \\
\hline
\end{tabular}

Ao atingirem $12 \%$ de umidade, os frutos de cada tratamento foram acondicionados hermeticamente até o momento da avaliação do rendimento quando, cada fruto foi pesado individualmente e, a seguir, seus grãos removidos e pesados, tendo sido considerados somente os frutos contendo dois grãos normais tipo chato. O rendimento intrínseco (RI) foi obtido pela fórmula RI = massa de dois grãos tipo chato/massa total do fruto seco) x 100. O número de frutos colhidos em cada germoplasma de um mesmo grupo foi o mesmo. Entretanto, o número final considerado para as análises, parâmetros estatísticos e confecção dos gráficos de caixa foi variável, pois somente foram considerados o rendimento daqueles frutos, contendo dois grãos normais tipo chato, e descartados os frutos com grão moca ou com uma ou duas lojas vazias. 


\subsection{Parâmetros e análises estatísticas}

Visando ilustrar a variabilidade dos diversos materiais e amostras estudadas obtiveram-se, com o auxilio do programa estatístico MINITAB (2000), versão 13, além das análises de variância e intervalos de confiança da média (Tukey a $95 \%$; $\alpha=0,05$ ), os desvios-padrão, coeficientes de variação experimental e gráficos de caixa mostrando a distribuição dos valores. Nos gráficos de caixa utilizados para melhor visualização dos resultados, constam a média, mediana, quartis $(Q)$ e valores discrepantes (Figura 1). Conforme o grupo de experimento estudado, os delineamentos experimentais utilizados foram o inteiramente casualizado (DIC), considerando cada fruto uma repetição ou o hierárquico com dados totalmente aninhados (DHTA). Nesse último caso, considerou-se cada fruto como amostra dos respectivos tratamentos, com efeitos aleatórios, sendo os resultados analisados e estatisticamente testados, com base nos respectivos componentes de variância de cada delineamento.

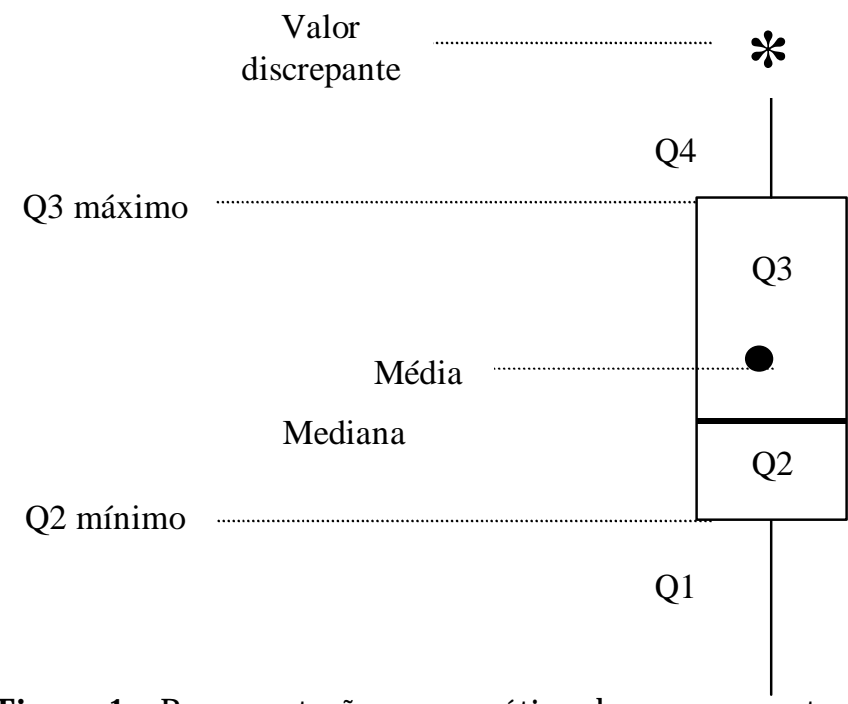

Figura 1 . Representação esquemática dos componentes do gráfico de caixa mostrando de forma padronizada a distribuição de cada amostra em relação à média, mediana, os valores $25 \%$ menores $\left(Q_{1}\right)$ e maiores $\left(Q_{4}\right)$, assim como os $50 \%$ valores centrais $\left(Q_{2}+Q_{3}\right)$ identificando também os discrepantes $\left[ \pm 1,5\left(Q_{3 \max }-Q_{2 \min }\right)\right]$.

\section{RESULTADOS E DISCUSSÃO}

\subsection{Grupo 1: Cultivares de C. arabica de porte baixo-CEC}

As cinco cultivares de porte baixo mostraram rendimentos intrínsecos significativamente diferentes (Tabelas 3 e 4; Figura 2). A maior diferença entre as cultivares desse grupo foi de $9,5 \%$. As cultivares
Obatã IAC 1669-20 e Tupi IAC 1669-33 apresentaram valores de rendimento próximos $(45,5 \%$ e $46,6 \%$ respectivamente), mais baixos se comparados aos de Catuaí Vermelho (IAC 144 e IAC 81) e Ouro Verde H 5010-5, sendo a última, a de mais alto rendimento (55\%). As cultivares Obatã e Tupi são geneticamente bastante relacionadas entre si, possuindo origem comum de um "Sarchimor" (FAzUOLI et al., 1999). As duas cultivares de Catuaí Vermelho são geneticamente muito relacionadas e também apresentaram valores bem mais próximos entre si que entre as demais cultivares. A cultivar Ouro Verde IAC H 5010-5, derivada de um cruzamento de uma linhagem de Catuaí Amarelo com a cv. Mundo Novo IAC 515-20 (FAzUOLI et al., 2000) é, geneticamente, a menos relacionada às demais desse grupo e a mais discrepante, com o mais alto rendimento $(55 \%)$. Esses resultados vem indicar a importância da constituição genética na característica rendimento intrínseco.

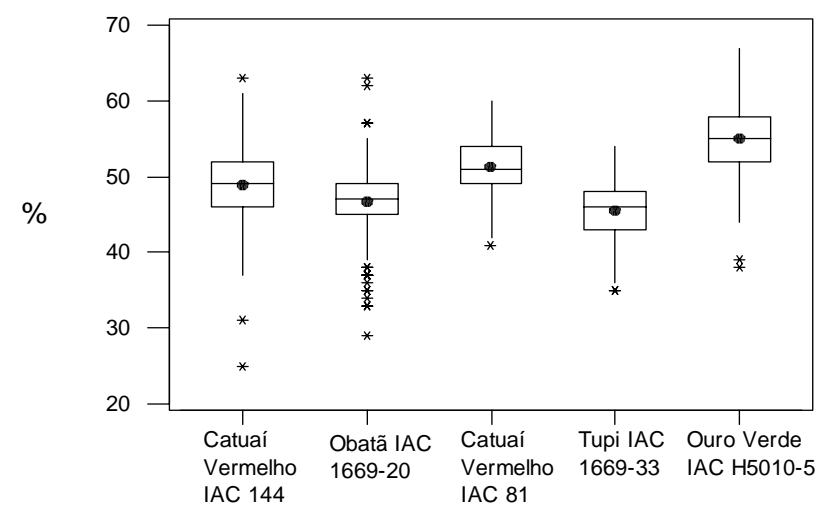

Figura 2. Distribuição dos valores de rendimento intrínseco de frutos de cultivares de porte baixo de C. arabica, analisadas no Grupo 1.

\subsection{Grupo 2: Cultivares e seleções de C. arabica - Fa- zenda Monte D'Este}

Os resultados da avaliação do rendimento nas várias cultivares e seleções de $C$. arabica obtidas do campo experimental na Fazenda Monte D'Este, em Campinas, são apresentados nas Tabelas 5 e 6 e Figura 3.

A cultivar Tupi IAC 4096, as seleções Broto Bronze e Broto Verde de 'Icatu Amarelo IAC 2944' apresentaram os menores rendimentos, com valores de 48,5; 49,9 e 49,4 respectivamente. Os maiores rendimentos foram observados na cultivar Mundo Novo IAC 388-17-1, Catuaí Vermelho IAC 46 e Icatu Amarelo IAC 2944 seleção 7A, com valores de 58,5; 58,9 e $57,8 \%$ respectivamente. Essas diferenças são, em grande parte, devido às diferenças genéticas existentes entre os materiais, sendo interessante notar o fato 
Tabela 3. Análise de variância e coeficiente de variação experimental (C.V.) dos valores de rendimento intrínseco de cultivares de C. arabica analisadas no Grupo 1

\begin{tabular}{lrrr}
\hline FV & GL & QM & F \\
\hline Cultivar & 4 & 4018,9 & $223,35^{* *}$ \\
Erro & 1407 & 18,0 & \\
Total & 1411 & 4036,9 & \\
\hline
\end{tabular}

C.V. $8,6 \%$

** significativo a $1 \%$ de probabilidade.

Tabela 4. Número de frutos (N), porcentagem média de rendimento intrínseco, desvio-padrão e intervalo de confiança da média (Tukey 95\%) de cultivares de C. arabica, analisados no Grupo 1.

\begin{tabular}{|c|c|c|c|c|c|c|c|c|}
\hline Cultivar & $\mathrm{N}$ & Média & Desvio- padrão & \multicolumn{5}{|c|}{ Intervalo de confiança } \\
\hline Catuaí Vermelho IAC 144 & 261 & 48,99 & 5,073 & & & $(*-)$ & & \\
\hline Obatã IAC 1669-20 & 325 & 46,63 & 4,134 & & $(*-)$ & & & \\
\hline Catuaí Vermelho IAC 81 & 289 & 51,29 & 3,786 & $\left(\right.$ - $\left.^{*}\right)$ & & & & \\
\hline Tupi IAC 1669-33 & 259 & 45,51 & 3,478 & & & & $\left(\right.$ 一 $\left.^{*}\right)$ & \\
\hline \multirow[t]{2}{*}{ Ouro Verde IAC H5010-5 } & 278 & 54,96 & 4,592 & & & & & $(*-)$ \\
\hline & & & & $\begin{array}{l}-+- \\
45.0\end{array}$ & & -+—- & 51.0 & - \\
\hline
\end{tabular}

Tabela 5. Análise de variância e coeficiente de variação experimental (CV) dos valores de rendimento intrínseco de cultivares e seleções de C. arabica, avaliadas no Grupo 2.

\begin{tabular}{lrrr}
\hline FV & GL & QM & F \\
\hline Cultivar/Seleção & 21 & 401,2 & $14,52^{* *}$ \\
Erro & 1.465 & 27,6 & \\
Total & 1.486 & 428,8 & \\
\hline
\end{tabular}

C.V. $9,5 \%$

** significativo a $1 \%$ de probabilidade.

de as seleções Broto Bronze e Broto Verde de "Icatu Amarelo" terem mostrado valores de rendimentos, muito semelhantes, estatisticamente não significativos e, serem também materiais geneticamente muito relacionados, pois se tratam de progênies irmãs que, por estarem segregando para coloração das folhas novas, foram selecionadas na geração anterior ${ }^{(6)}$.

$\left({ }^{6}\right)$ L.C. FAZUOLI (Informação pessoal).
Outros casos com genealogia e rendimentos bastante semelhantes são os das seleções Catucaí Vermelho MAPA $(55,3 \%)$ e Catucaí Amarelo MAPA (56,3\%), Catuaí Amarelo IAC 47 (55,1\%), Catuaí Amarelo IAC 62 (56,3\%) e Catuaí Amarelo IAC 100 (55,9\%) e das seleções 'Icatu Vermelho' IAC 4041, IAC 4043, IAC 4045 e IAC 4046 que variaram de 53,9\% a 56,7\%, com diferenças também não significativas. Por outro lado, diferenças significativas foram observadas entre os rendimentos das cultivares Icatu Amarelo IAC 2944-6 (54,1\%) e Icatu Amarelo IAC 2944-7A (57,8\%) com marcantes diferenças verificadas entre o Catuaí Vermelho IAC 81 (53,7\%) e o Catuaí Vermelho IAC 46 (58,9\%). 
Tabela 6. Número de frutos (N), porcentagem média de rendimento intrínseco, desvio-padrão e intervalo de confiança da média (Tukey 95\%) de cultivares e seleções de C. arabica, avaliadas no Grupo 2

\begin{tabular}{|c|c|c|c|c|c|c|}
\hline Identificação & Cultivar/Seleção & $\mathrm{N}$ & Média & Desvio-padrão & & Intervalo de confiança \\
\hline & & & $\%$ & & & \\
\hline 1 & Bourbon Amarelo & 73 & 55,62 & 3,995 & & $($ (一 一 一 $)$ \\
\hline 2 & M. N. Vermelho & 83 & 58,48 & 6,327 & & $($ (一一一) \\
\hline 3 & Acaiá & 76 & 56,29 & 5,640 & & $\left(\right.$ — $^{*}$ - $)$ \\
\hline 4 & Ouro Verde & 76 & 55,26 & 5,211 & & $($ (一一一) \\
\hline 5 & Catuaí Verm. 46 & 77 & 58,88 & 3,273 & & $($ (一一一) \\
\hline 6 & Catuaí Verm. 81 & 74 & 53,69 & 4,913 & & $($ 一一 一一) \\
\hline 7 & Catuaí Verm. 99 & 75 & 56,39 & 4,030 & & $($ (一 一一) \\
\hline 8 & Catuaí Am 47 & 69 & 55,09 & 5,428 & & $($ (一 一一) \\
\hline 9 & Catuaí Am. 62 & 69 & 56,28 & 4,287 & & $($ (一一一) \\
\hline 10 & Catuaí Am. 100 & 73 & 55,89 & 4,739 & & $($ (一一 - $)$ \\
\hline 11 & Obatã & 73 & 52,67 & 5,897 & & $($ (一一一) \\
\hline 12 & Tupi & 39 & 48,49 & 4,822 & $\left(\square^{*}-\right)$ & \\
\hline 13 & Catucaí Vermelho & 72 & 56,33 & 3,857 & & $($ (一 一一) \\
\hline 14 & Catucaí Amarelo & 70 & 55,30 & 6,651 & & $($ (一一一) \\
\hline 15 & Icatu Ver 4041 & 73 & 53,90 & 5,805 & & $\left(\left(^{*}\right.\right.$ - $)$ \\
\hline 16 & Icatu Ver 4043 & 61 & 55,36 & 5,444 & & $($ (一一一) \\
\hline 17 & Icatu Verm. 4045 & 67 & 54,84 & 6,651 & & $\left(\right.$ 一 $^{*}$ - $)$ \\
\hline 18 & Icatu Verm. 4046 & 68 & 56,56 & 5,634 & & $($ (一 一一) \\
\hline 19 & Icatu Am. Broto Bronze & 55 & 49,91 & 4,703 & $($ (———) & \\
\hline 20 & Icatu Am. Broto Verde & 41 & 49,37 & 6,184 & $($ (一一一) & \\
\hline 21 & Icatu Am. 2944-6 & 63 & 54,05 & 4,520 & & $($ (一一一) \\
\hline \multirow[t]{2}{*}{22} & Icatu Am. 2944-7A & 60 & 57,78 & 6,170 & & $\left(\right.$ ——— $\left.{ }^{*}\right)$ \\
\hline & & & & & 48.0 & 56.0 \\
\hline
\end{tabular}

Merecem destaque sob o aspecto genético, portanto, tanto as similaridades quanto as diferenças de rendimento intrínseco observadas entre as várias cultivares e seleções bastante relacionadas genealogicamente. Esse fato vem indicar, por um lado, a fidelidade esperada na expressão genética deste caráter e, por outro, sua relação com uma possível segregação dos genes responsáveis por essa característica. Essas observações sugerem ser, o rendimento intrínseco, uma característica passível de seleção e, talvez, de caracterização de cultivares, haja vista a amplitude de 9,5\% nos valores observados entre as 22 cultivares e seleções investigadas nesse grupo experimental.

\subsection{Grupo 3: Variedades e formas botânicas, híbri- dos, acessos e mutantes de C. arabica - Coleção no CEC}

Observou-se que existe ampla variabilidade entre os materiais desse grupo, tendo sido obtidos valores entre $42 \%$ a $64 \%$ (Tabelas 2,7 e 8 e Figura 4 ). As variedades botânicas comercialmente cultivadas mostraram rendimentos intermediários, entre $47,0 \%$ a $56,9 \%$. Os mais altos rendimentos, acima de $58 \%$, foram observados em Nacional (59,3\%), 1109-3 (60,2\%), 1142-1 (63,9\%), Anômala (60,2\%), Abramulosa (63\%), Híbrido de Timor (58,4\%), Cera (58,1\%) e Abissínica $(59,6 \%)$, notando-se que todos são pouco produtivos. 
Entre os de mais baixo rendimento, na faixa de $42,3 \%$ a $46,1 \%$, estão BA 27 (49,9\%), Icatu Vermelho $(44,7 \%)$, Polisperma (43,6\%), Icatu Caturra (43,2\%), Catimor $(46,1 \%)$ e Macrodiscus (42,3\%). Entre esses últimos, Polisperma e Macrodiscus são mutantes que têm, especificamente, as características dos frutos afetadas. Os demais compreendem acessos e formas antigas de variedades cuja única semelhança é o fato de terem remotamente, na genealogia, origem em uma hibridação interespecífica, no caso BA 27 de C. liberica var. liberica e Icatu Vermelho, Icatu Caturra e Catimor de C. canephora. Note-se que C. liberica var. liberica e C. canephora foram as espécies que apresentaram, respectivamente, os mais baixos e os mais altos rendimentos intrínsecos (Tabela 14).

Entre os derivados de C. canephora, espécie de alto rendimento, encontram-se representantes de baixo rendimento como duas da cv. Icatu e uma da Catimor e também de alto rendimento como o Híbrido de Timor. É, entretanto, alvo de maiores conjecturas o fato de o Híbrido de Timor ser o de mais alto rendimento e possuir a maior proporção de genoma de $C$. canephora.

\subsection{Grupo 4: Seleções de C. canephora var. kouilou - BAG no CEC}

A variedade kouilou de C. canephora foi introduzida do Estado do Espírito Santo no IAC há mais de 50 anos. Constitui-se na principal cultivar de café do tipo robusta cultivada no Brasil. Naquele Estado, foi submetida a vários ciclos de seleção, porém, é comum ainda, lavouras antigas dessa cultivar apresentando considerável variabilidade para características dos frutos e grãos, resistência à ferrugem (Hemileia vastatrix), porte, perfilhamento e facilidade de enraizamento.

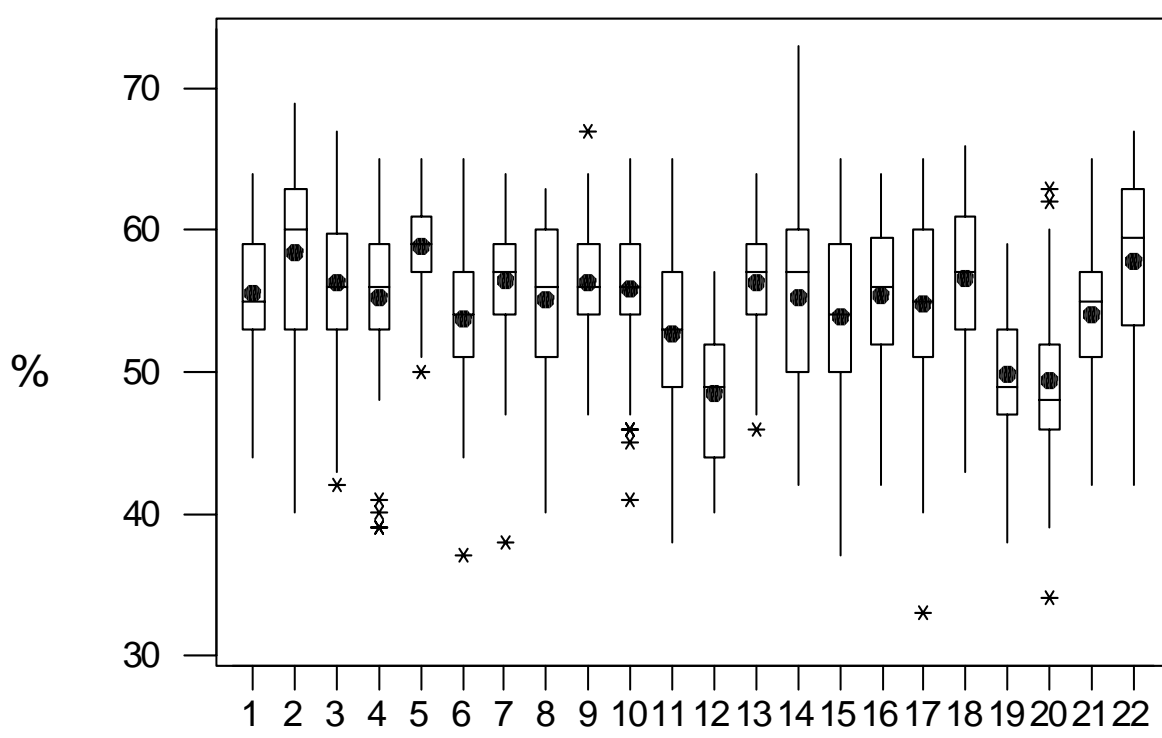

1 - Bourbon Amarelo IAC LCJ-18

2 - Mundo Novo Vermelho IAC 388-17-1

3 - Acaiá IAC 474-10

4 - Ouro Verde IAC 4395

5 - Catuaí Vermelho IAC 46

6 - Catuaí Vermelho IAC 81

7 - Catuaí Vermelho IAC 99

8 - Catuaí Amarelo IAC 47

9 - Catuaí Amarelo IAC 62

10 - Catuaí Amarelo IAC100

11 - Obatã IAC 4092

12 - Tupi IAC 4096

13 - Catucaí Vermelho MAPA

14 - Catucaí Amarelo MAPA

15 - Icatu Vermelho IAC 4041

16 - Icatu Vermelho IAC 4043

17 - Icatu Vermelho IAC 4045

18 - Icatu Vermelho IAC 4046

19 - Icatu Amarelo IAC 2944 Broto Bronze

20 - Icatu Amarelo IAC 2944 Broto Verde

21 - Icatu Amarelo IAC 2944-6

22 - Icatu Amarelo IAC 2944-7A

Figura 3. Distribuição dos valores de rendimento intrínseco em plantas de cultivares e seleções de C. arabica, analisadas no Grupo 2.

Tabela 7. Análise de variância e coeficiente de variação experimental (C.V.) dos valores de rendimento intrínseco de variedades e formas botânicas, híbridos, acessos e mutantes de C.arabica, avaliadas no Grupo 3

\begin{tabular}{lccc}
\hline FV & GL & QM & F \\
\hline Genótipo & 78 & 846,0 & $38,89^{* *}$ \\
Erro & 4.265 & 21,8 & \\
Total & 4.343 & 867,8 & \\
\hline
\end{tabular}

C.V. $8,8 \%$

** significativo a $1 \%$ de probabilidade. 
Tabela 8. Número de frutos $(\mathrm{N})$, porcentagem média de rendimento intrínseco, desvio-padrão e intervalo de confiança da média (Tukey 95\%) de variedades e formas botânicas, híbridos, acessos e mutantes de C. arabica do Banco Ativo de Germoplasma (BAG) analisados no Grupo 3.

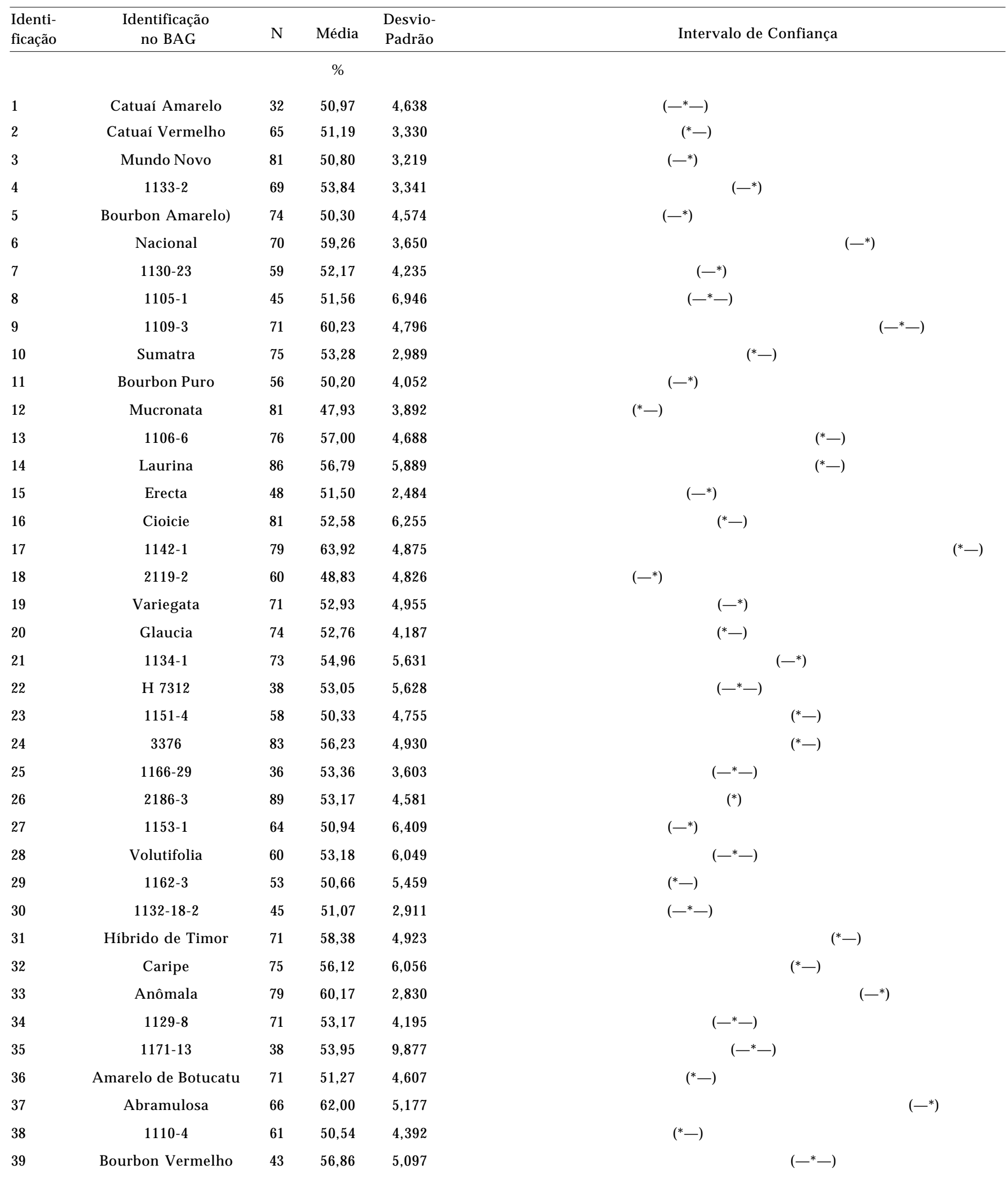


Tabela 8. Conclusão

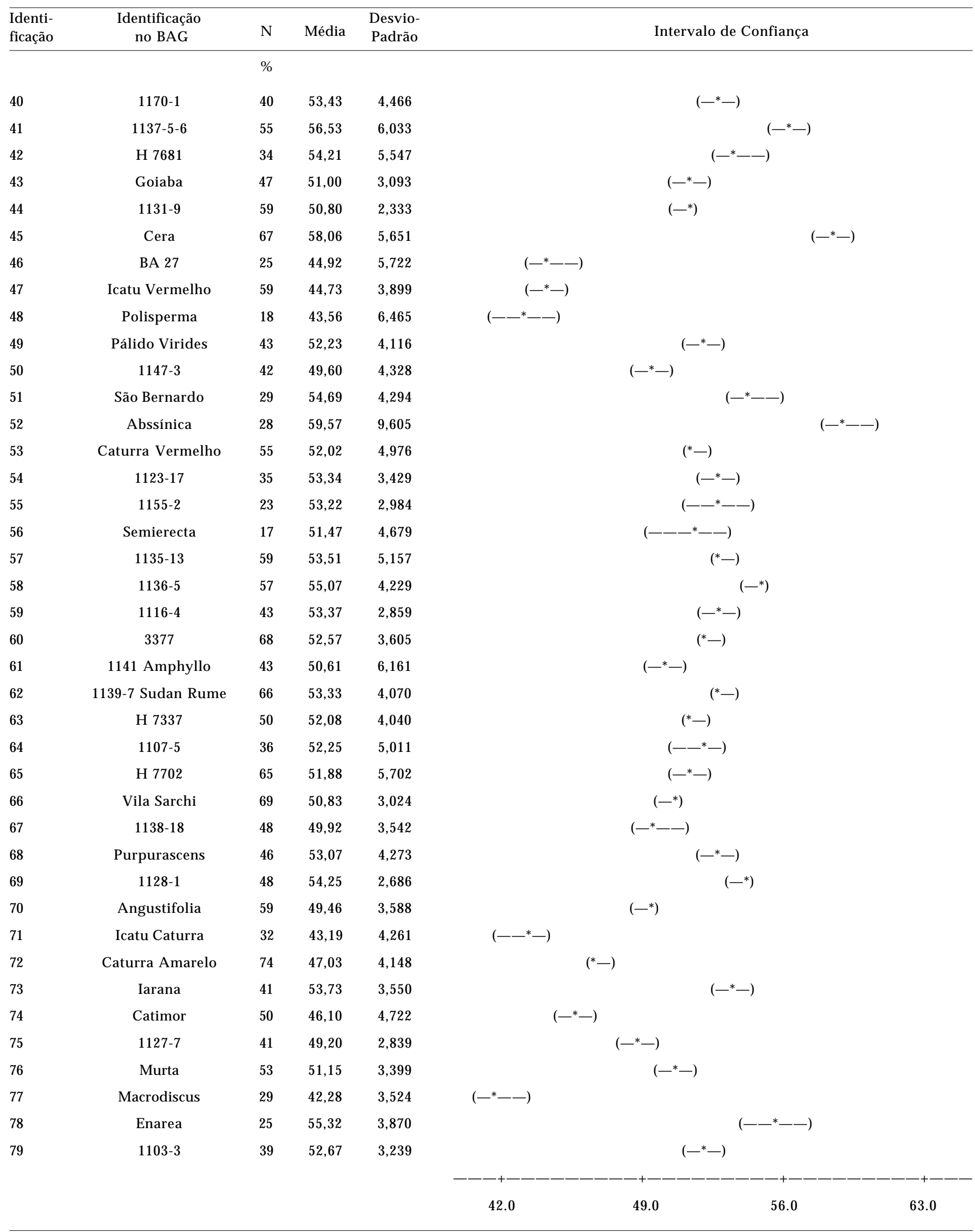


Entre os três acessos investigados, a seleção IAC 66 foi a de menor rendimento $(57,8 \%)$ e o maior $(61,3 \%)$ observado na seleção IAC 68 (Tabelas 9 e 10 e Figura 5). Esses valores são relativamente altos quando comparados aos cafés do tipo arábica e corroboram o que se conhece na prática de que o café robusta "rende" mais que o café arábica. Cramer (1957), CAPOT
(1972) e Veneziano (1993) mencionam também o superior rendimento em coco/beneficiado do café robusta em relação ao café arábica.

A variação de $3,6 \%$ no rendimento médio entre as três seleções da variedade kouilou de C. canephora reflete pequena, mas significativa diferença genética entre elas.

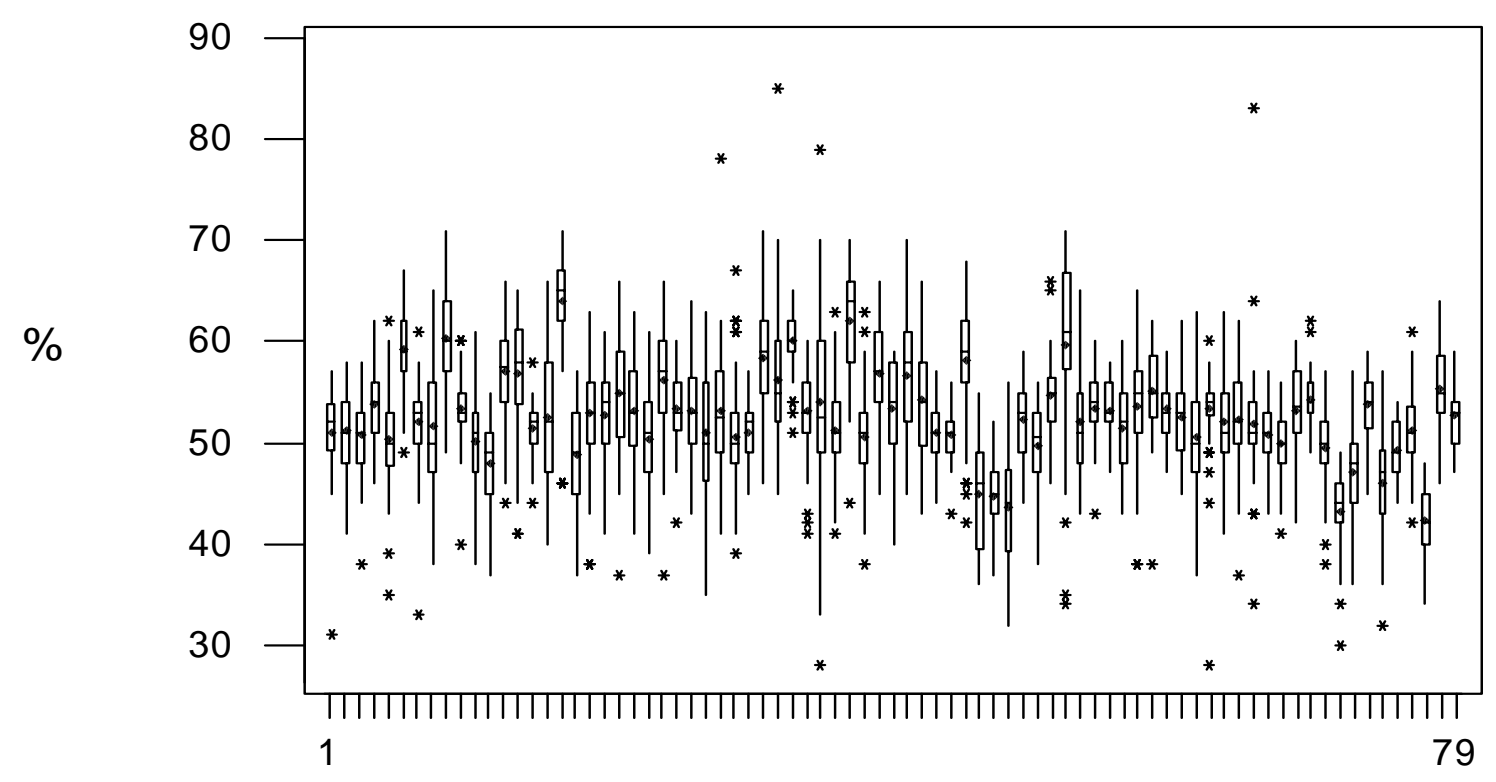

Figura 4. Distribuição dos valores de rendimento intrínseco de frutos de 79 germoplasmas compreendendo variedades e formas botânicas, acessos, híbridos e mutantes de C. arabica, analisadas no Grupo 3 e indicadas na Tabela 2.

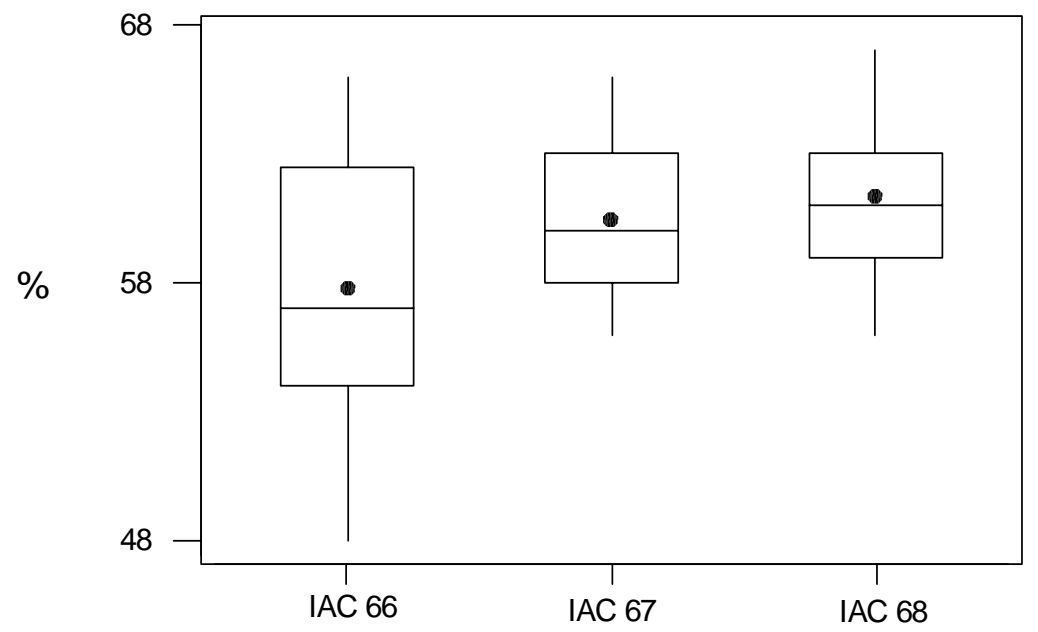

Figura 5. Distribuição dos valores de rendimento intrínseco de acessos da var. kouilou de C. canephora, analisadas no Grupo 4. 
Tabela 9. Análise de variância e coeficiente de variação experimental (C.V.) dos valores de rendimento intrínseco de seleções de C. canephora var. kouilou avaliadas no Grupo 4

\begin{tabular}{lrrr}
\hline FV & GL & QM & F \\
\hline Seleção & 2 & 125,4 & $9,74^{* *}$ \\
Erro & 126 & 12,9 & 138,3 \\
Total & 128 & & \\
\hline
\end{tabular}

C.V. $6,0 \%$

**significativo a $1 \%$ de probabilidade.

Tabela 10. Número de frutos $(\mathrm{N})$, porcentagem média de rendimento intrínseco, desvio padrão e intervalo de confiança da média (Tukey 95\%) de seleções de C. canephora var. kouilou avaliadas no Grupo 4

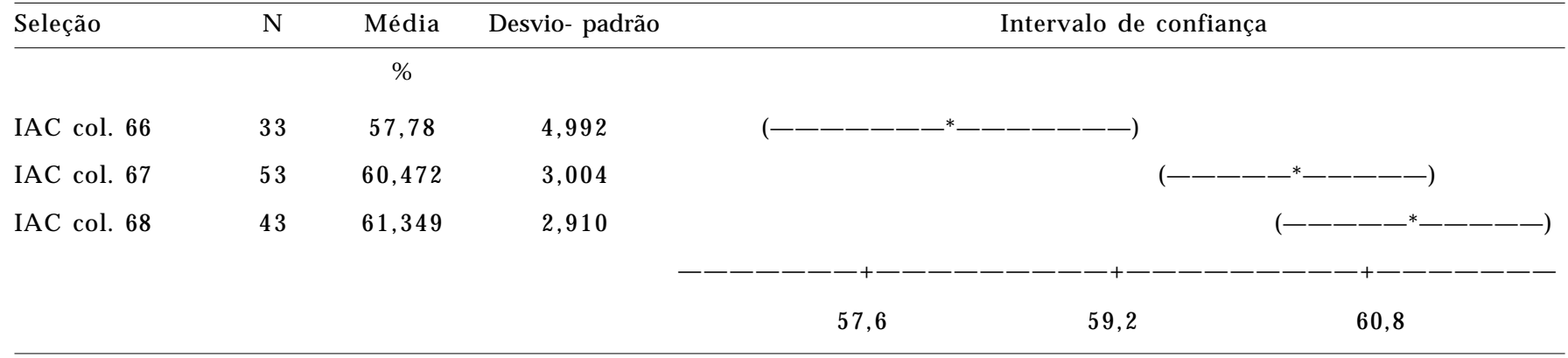

\subsection{Grupo 5: Acessos de C. canephora - Ensaio no CEC}

Entre os 10 acessos de C. canephora var. robus$t a$, verificou-se variação de $48,4 \%$ a $61,9 \%$, diferença de $13,6 \%$ nos valores para rendimento intrínseco, o que ilustra a considerável variabilidade existente nesse material (Tabelas 11 e 12; Figura 6).

\subsection{Grupo 6: Espécies de Coffea-BAG no CEC}

Conforme os resultados apresentados nas Tabelas 13, 14 e na Figura 7, em que são analisados representantes de 10 espécies diplóides de Coffea do Banco de Germoplasma do IAC, verifica-se existir grande variabilidade para o rendimento intrínseco entre as espécies. Foram obtidos valores entre 30,2\% e $61,3 \%$. Essa diferença de $31,1 \%$ entre os representantes desse grupo foi maior que entre os representantes de todos os outros grupos aqui investigados. C. liberica var. liberica apresentou o menor rendimento intrínseco, devido à grande espessura da casca. Os representantes dessa espécie no BAG têm frutos verdes, grandes, com um pericarpo visivelmente espesso.

\subsection{Considerações finais}

A análise geral dos diversos grupos investigados revela que quanto maior a diversidade e o número de genótipos de cada grupo estudado, maiores foram as diferenças significativas observadas entre os valores de rendimento intrínseco. Observou-se ampla variabilidade genética, tanto em C. arabica quanto em $C$. canephora, sendo os valores dessa última, bem superiores aos da primeira. Em C. arabica, os valores de rendimento intrínseco observados no extenso germoplasma estudado não revelou associação desta característica com níveis de produtividade, qualidade da bebida ou resistência à ferrugem dos diversos materiais, haja vista existirem representantes contrastantes para rendimentos intrínsecos e para todas essas características. As diferenças entre os valores das várias espécies do gênero Coffea, foram bem maiores que aquelas referentes aos germoplasmas de C. arabica ou de C. canephora. Nos germoplasmas derivados de hibridações interespecíficas de C. arabica com C. canephora ou com C. liberica var. liberica, observou-se também ampla variabilidade, verificando-se material de origem comum, porém, como os parentais, exibindo marcantes diferenças nos valores de rendimento intrínseco.

Esse fato sugere possível segregação e fixação dos fatores genéticos que controlam essa característica. Essas variações genéticas observadas revelam que o rendimento intrínseco pode ser utilizado no melhoramento como um critério adicional de seleção, controladas, entretanto, as influências ambientais que o afetam. 
Tabela 11. Análise de variância e coeficiente de variação experimental (C.V.) dos valores de rendimento intrínseco de acessos de C. canephora var. robusta, avaliadas no Grupo 5.

\begin{tabular}{lrrr}
\hline FV & GL & QM & F \\
\hline Acesso & 9 & 1771,20 & $4,86^{*}$ \\
Planta & 10 & 364,52 & $30,48^{* *}$ \\
Erro & 1059 & 11,96 & 2147,7 \\
Total & 1078 & & \\
\hline
\end{tabular}

C.V. $6,2 \%$

* significativo a $5 \%$ de probabilidade ${ }^{* *}$ significativo a $1 \%$ de probabilidade.

Tabela 12. Número de frutos $(\mathrm{N})$, porcentagem média de rendimento intrínseco, desvio padrão e intervalo de confiança da média (Tukey 95\%) de acessos de C. canephora var. robusta, avaliados no Grupo 5.

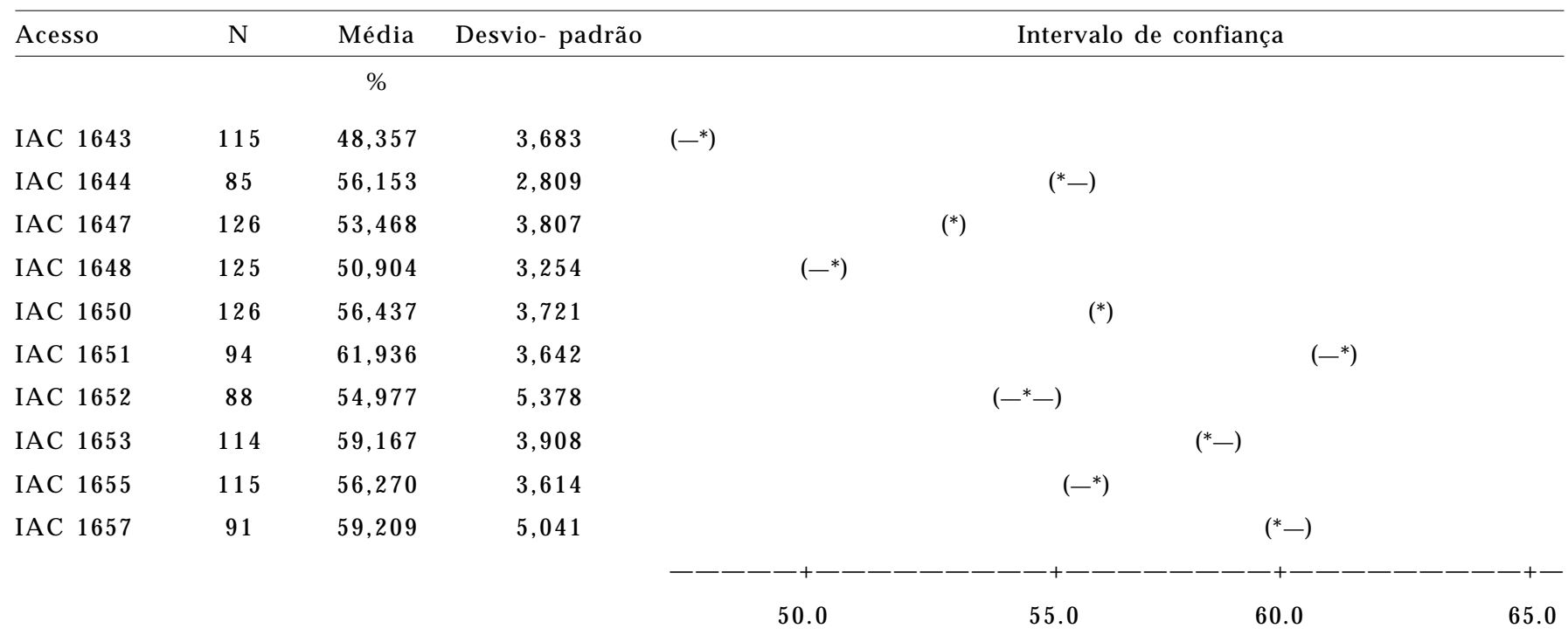

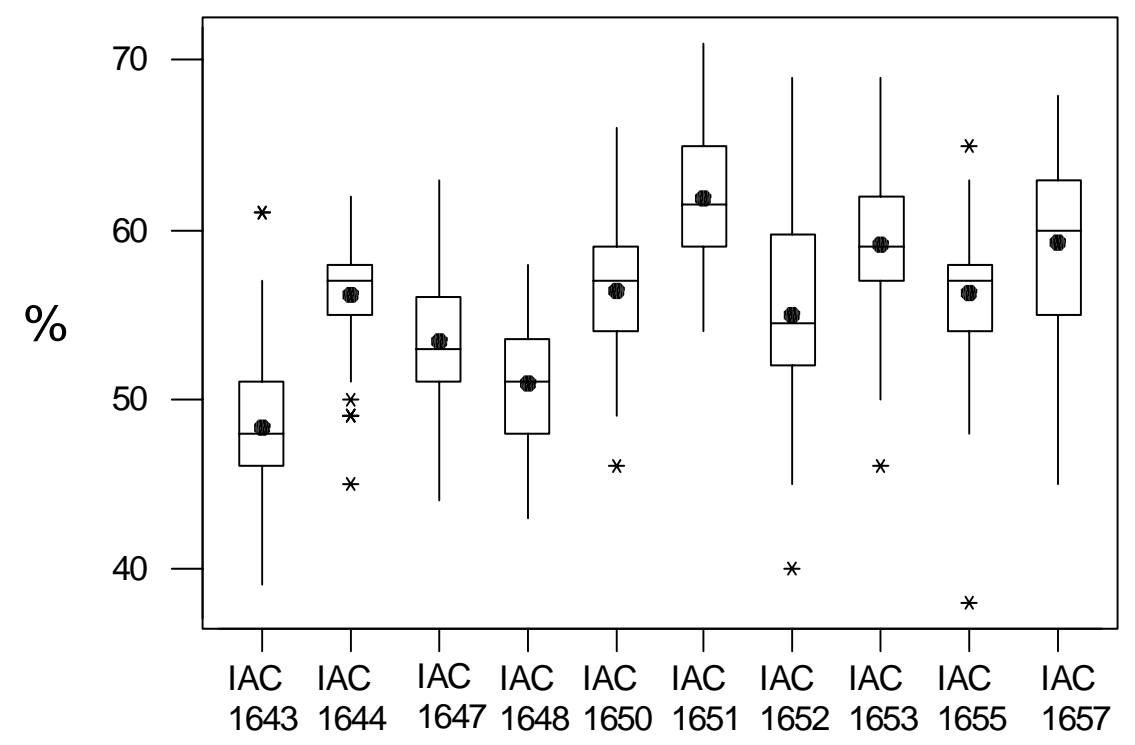

Figura 6. Distribuição dos valores de rendimento intrínseco de acessos de C. canephora, var. robusta, analisadas no Grupo 5. 
Tabela 13. Análise de variância e coeficiente de variação experimental (C.V.) dos valores de rendimento intrínseco de frutos de espécies de Coffea, avaliadas no Grupo 6

\begin{tabular}{lrrr}
\hline FV & GL & QM & F \\
\hline Espécie & 9 & 4450,3 & $203,40^{* *}$ \\
Erro & 486 & 21,9 & \\
Total & 495 & 4472,2 & \\
\hline
\end{tabular}

C.V. $9,2 \%$

**significativo a $1 \%$ de probabilidade.

Tabela 14. Número de frutos (N), porcentagem média de rendimento intrínseco, desvio-padrão e intervalo de confiança da média (Tukey 95\%) de espécies de Coffea avaliadas no Grupo 6

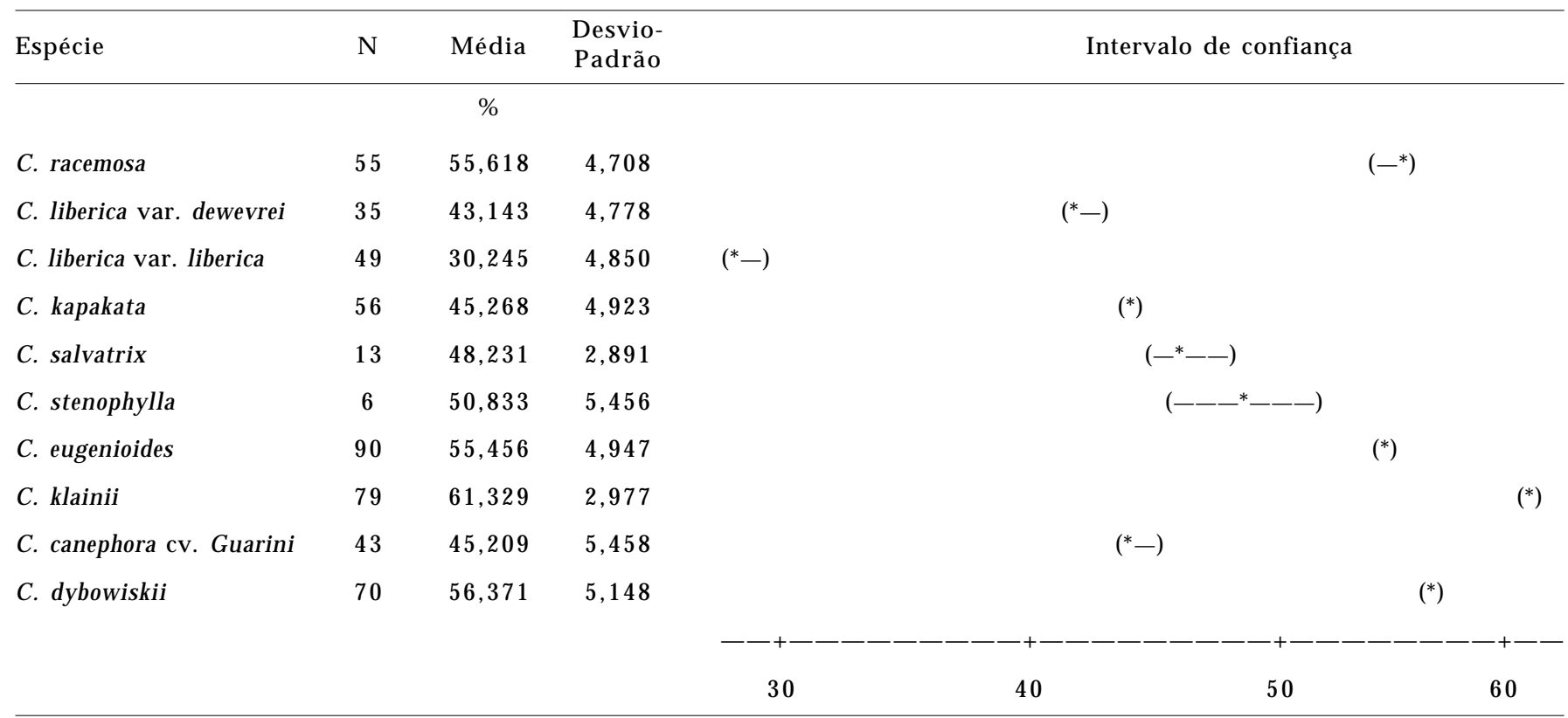

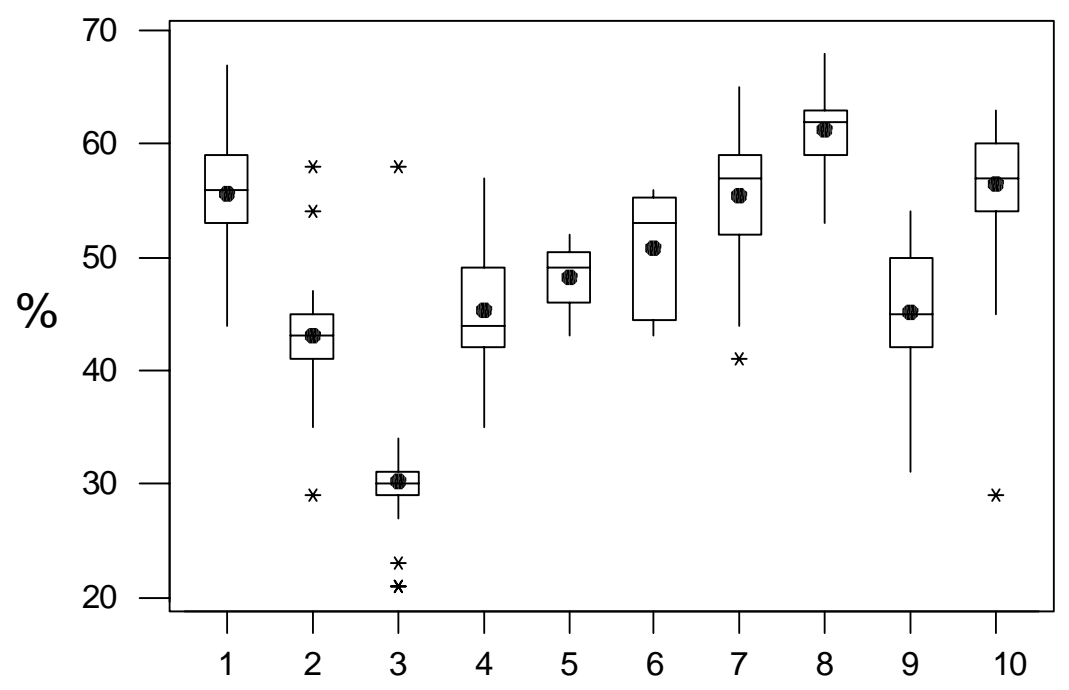

1- Coffea racemosa

2- C. liberica var. dewevrei

3- C. liberica var. liberica

4- C. kapakata

5- C. salvatrix

6- C. stenophylla

7- C. eugenioides

8- C. klainii

9- C. canephora cv. Guarini

10- C. dybowiskii

Figura 7. Distribuição dos valores de rendimento intrínseco de frutos de espécies do gênero Coffea, analisadas no Grupo 6. 
Um estudo de vários fatores ambientais que podem influenciar o rendimento intrínseco ${ }^{(7)}$ atestou que a seleção para essa característica deve ser realizada em amostras padronizadas do maior número possível de plantas pertencentes à progênies uniformes.

\section{CONCLUSÕES}

1. Existe variabilidade genética para a característica rendimento intrínseco nas cultivares, seleções, acessos, variedades botânicas, formas e mutantes de C. arabica, assim como nas seleções e acessos de $C$. canephora e em outras espécies do gênero Coffea.

2. No germoplasma estudado, o rendimento intrínseco variou de $30,2 \%$ a $63,9 \%$.

3. Sugere-se que o rendimento intrínseco seja utilizado como critério adicional de seleção no melhoramento do cafeeiro.

\section{AGRADECIMENTOS}

Os autores agradecem a I.B. Baziolli, S.L.S. Lima, R.C. Gregol, AT.E. Aguiar, R. Moreira, E.A.P. Barbosa, C.J. Cipriano, O.S. Campos pelo auxílio na obtenção dos dados; ao Dr. L.A. Ambrósio e Dr. A. Conagin pela ajuda nas análises estatísticas e ao Dr. O. Guerreiro Filho pelo auxílio nas discussões.

\section{REFERÊNCIAS}

BERTHAUD, J. L'incompatibilite chez Coffea canephora: méthode de test et déterminisme génétique. Café Cacao e Thé, Paris, v.24, p.267-274, 1980.

BRIDSON, D.M. Studies in Coffea on Psilanthus (Rubiaceae subfam. Cinchonoideae) for part 2 of Flora of Tropical East Africa: Rubiaceae. Kew Bulletin, London, v.36, n.4, p.817-859, 1982.

BRIDSON, D.M. Nomenclature notes on Psilanthus, including Coffea sec. Paracoffea (Rubiaceae tribe Coffeae). Kew Bulletin, London, n.2, p.453-460, 1987.

BRIDSON, D.M. Additional notes on Coffea (Rubiaceae) from tropical East Africa. Kew Bulletin, London, v.49, n.2, p.331342, 1994.

BRIDSON, D.M.; VERDCOURT, B. Flora of tropical East Africa: Rubiaceae. (Part 2). Cape Town: Iziko Museums of Cape Town, 1988. p.415-747.

(7) C. Gaspari-Pezzopane; H.P. Medina Filho; R. Bordignon; W.J. Siqueira; P. Mazzafera (dados não publicados).
CAPOT, J. L'amélioration du caféir en Côte d'Ivoire. Les hybrides "Arabustas". Café Cacao e Thé, Paris, v.19, p.13-18, 1972.

CARVALHO, A.; FAZUOLI, L.C. Café. In: FURLANI, A.M.C.; VIEGAS, G.A. (Eds.). O melhoramento de plantas no Instituto Agronômico. Campinas: Instituto Agronômico, 1993. cap.2, p.29-76.

CARVALHO, A.; MONACO, L.C. Natural cross pollination in Coffea arabica. In: INTERNATIONAL HORTICULTURAL CONGRESS, 26., Brussels. Proceedings. Toronto: International Horticultural Society, 1962. v.4, p.447-449.

CHARRIER, A. La structure génétique des caféiers spontanés de la region Malgashe (Mascarocoffea). Leurs relations avec les caféiers d'origine africaine (Eucoffea). Paris, 1978. 223p. (Memories ORSTOM, 87).

CHEVALIER, A. Lês caféiers du globe. III. Systematique dês caféiers. Maladies et insects nuisibles. Encyclopedie biologique, Paris, v.28, n.3, p.1-256, 1947.

CONAGIN, C.H.T.M.; MENDES, A.J.T. Pesquisas citológicas e genéticas em três espécies de Coffea. Auto-incompatibilidade em Coffea canephora. Bragantia, Campinas, v.20, p.787-804, 1961.

CRAMER, P.J.S. A review of literature on coffee research in Indonesia. Turrialba: Interamerican Institute of Agricultural Science, 1957, 262p. (Miscelaneous. Publ. n.15).

FAZUOLI, L.C.; MEDINA FILHO, H.P.; GUERREIRO FILHO, O.; GONÇALVES, W.; SILVAROLA, M.B.; LIMA, M.M.A. de; CARVALHO, A. Cultivares de Café. Campinas: Instituto Agronômico, 1999. (Fôlder)

FAZUOLI, L.C.; MEDINA FILHO, H.P.; GUERREIRO FILHO, O.; GONÇALVES, W.; SILVAROLLA, M.B.; GALLO, P.B. Cultivares de café IAC apropriadas para o plantio adensado. Campinas: Instituto Agronômico, 2000. 5p. (Fôlder)

KRUG, C.A., MALAVOLTA, E., MORAES, F.R.P., DIAS, R.A., CARVALHO, A., MONACO, L.C., FRANCO, C.M., BERGAMIN, J., HEINRICH, W.O., ABRAHÃO, J., RIGITANO, A., SOUZA, O.F. de, FAVA, J.F.M. Cultura e adubação do cafeeiro. São Paulo: Instituto Brasileiro de Potassa, 1965. 277p.

LEBRUN, J. Recherches morphologiques et systématiques sur les caféiers du Congo. Publications de L'institut National Pour L“etude Agronomique du Congo Belge, 1941. 183p.

MEDINA FILHO, H.P.; CARVALHO, A.; SONDAHL, M.R.; FAZUOLI, L.C.; COSTA, W.M. Coffee breeding and related evolutionary aspects. In: JANICK, J. (Ed.). Plant Breeding Reviews. Westport: AVI Publishing, 1984. v.2, p.157-193.

MINITAB, INC. Meet Minitab Release 13,0 for Windows. State College, PA, 2000.

VACCARELLI, V.N.; MEDINA FILHO, H.P.; FAZUOLI, L.C. Relação entre rendimentos, frutos chochos e sementes tipo moca em diversos híbridos Arabusta. Bioscience Journal, Uberlândia, v.19, n.3, 2003 (no prelo).

VENEZIANO, W. Avaliação de progênies de cafeeiros (Coffea canephora Pierre ex. Froehner) em Rondônia. 1993. 78f. Tese (Doutorado) - Escola Superior de Agricultura 'Luiz de Queiroz' - USP, Piracicaba. 